\title{
تطبيق إدارة الجودة الشاملة في المستشفيات الخاصة
}

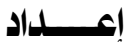

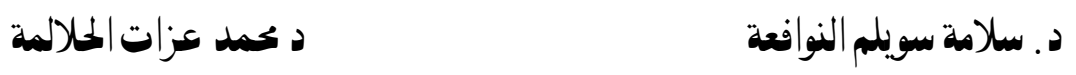

مجلة بحوث التربية النوعية - جامعة المنصورة

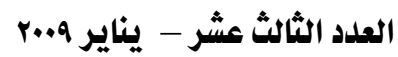




\section{تطبيقة إدارة الجودة الشاهلة في المستشفيات الخاصة}

دممد عزات الحلالمة
د ـ مامة سويلم النوافعة

\section{uall|}

تهدف هذه الدراسة إلى التعرف على تطبيق المستشفيات الخاصة الأردنية والصعوبات التي تواجهها ِِِ تطبيق إدارة الجودة الشاملة ، ولتحقيق غايات هذه الدراسـة تم تصميهم استبانه تتعلق

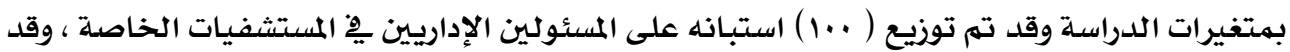

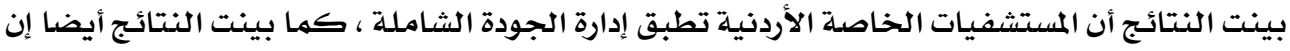

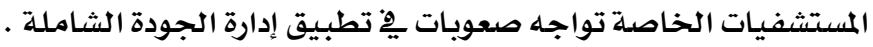

\section{همدمهة}

يعتبر مستوى الخدمات الصحية المقدمة للمواطنين من الأمور التي تدل على تقدم الدولة

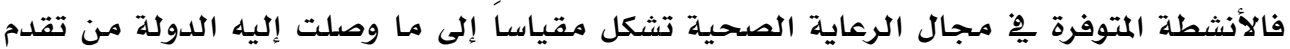

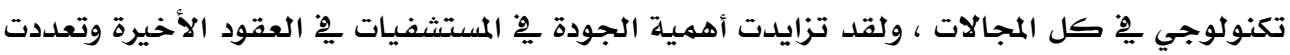

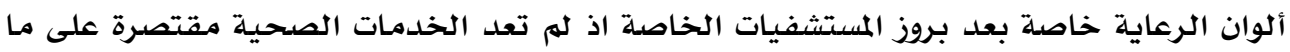

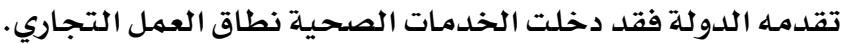
ولقد تزايد الطلب يِّ العقود الأخيرة وخاصة ِِّ المجتمعات المتقدمة على مختلف ألوان

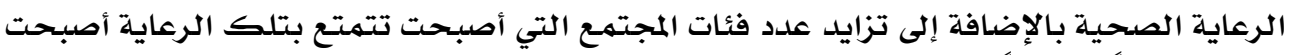

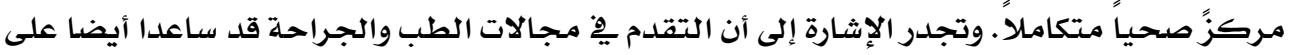

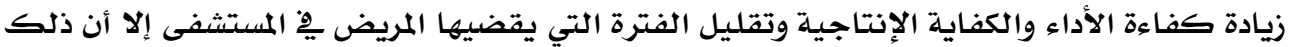

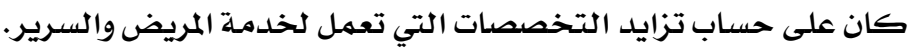
وغني عن الذكر ان المريض اليوم يسعى يِّ البداية إلى الحصول على خلدمة صحية متهيزة ، خاصة أولئك المرضى الذين يراجعون المستشفيات الخاصة والقادرين على دفع تكاليف العلاج، وهذا

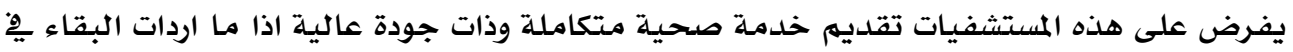
السوق والمحافظة على حصتها السوقية.

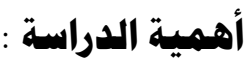

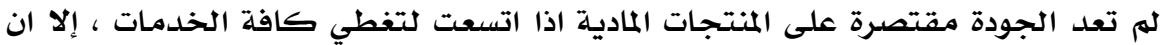

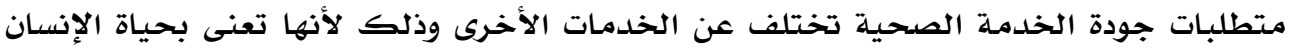

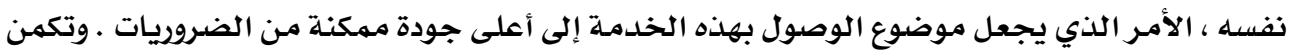

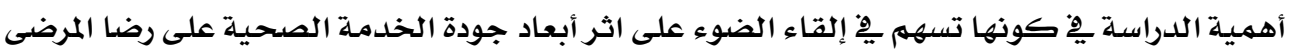


عن الخدمات الصحية التي تقدمها المستشفيات الخاصة يِّ الأردن، فضلا عن ندرة الدراسات التي

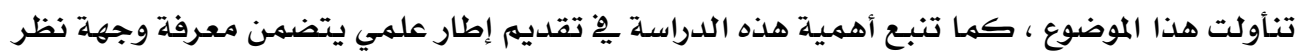

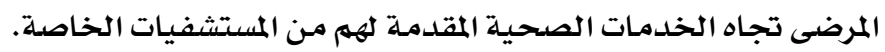

\section{هشكلة الدراسة}

شهدت العقود الأخيرة من القرن الماضي انتشار كبيرا للمستشفيات الخاصسة يِّ الأردن ، اذ اذ

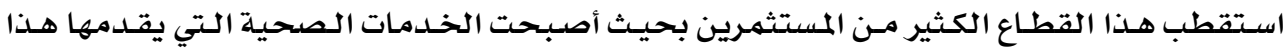

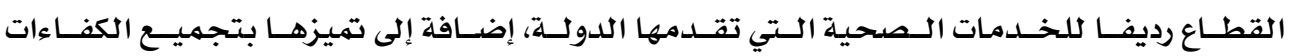

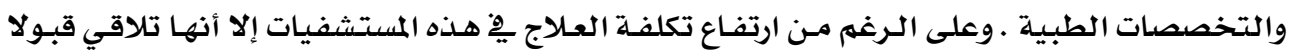

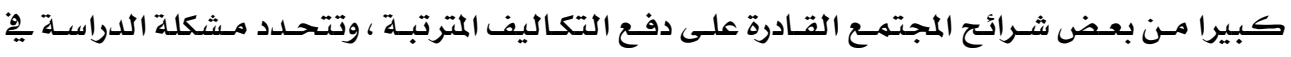

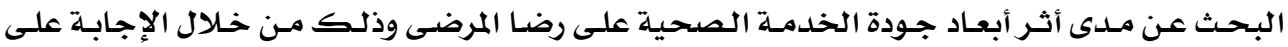
الأسئلة التالية :

1- هل تطبق المستشفيات الخاصلة إدارة الجودة الشاملة ؟

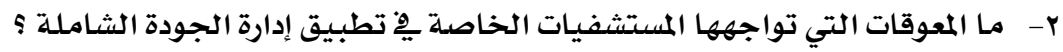

\section{أهداف الدراسة}

$$
\text { ا - التعرف علده الدراسة إلى تحقيق ما يلي : }
$$

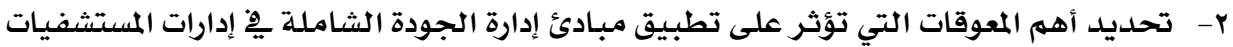

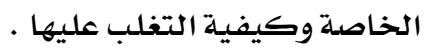

\section{الإطار النظري والدراسات السابقة}

\section{أ ـ الإطار النظري}

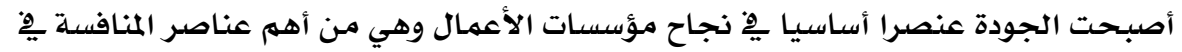

الأسواق المحلية والدولية ،وقد عرف المكتب القومي للتنمية الاقتصادية يِّ بريطانيا الجودة بأنها "

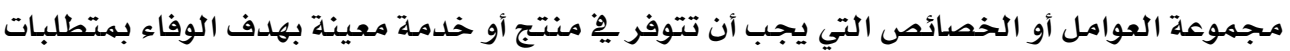

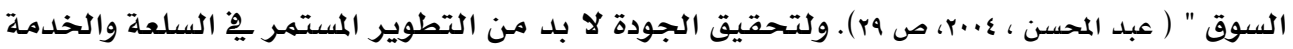

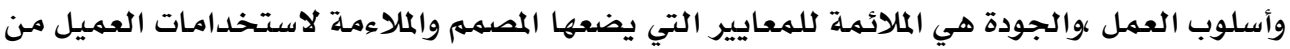

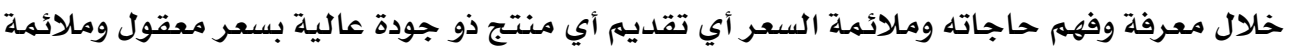

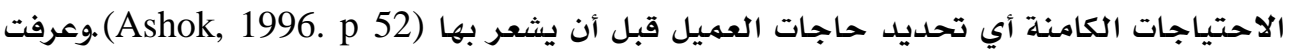

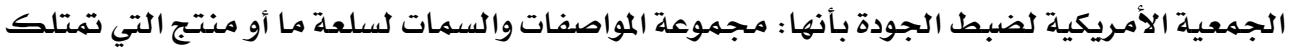

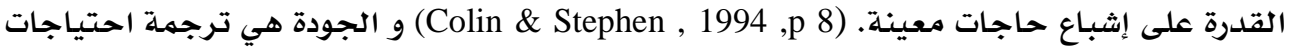

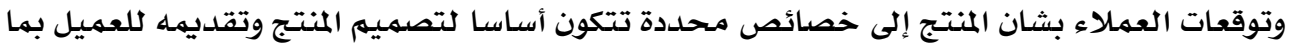


يوافق حاجاته وتوقعاته ، أما جودة الرعاية الصحية فتتلخص يِّ تطبيق العلوم والتقنيات الطبية

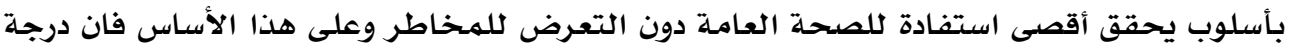

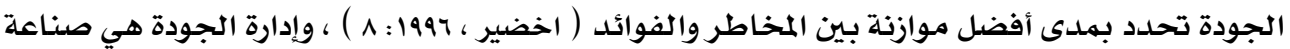

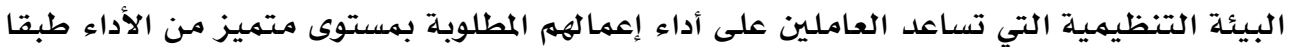
للمواصفات المطلوبة ، فهو الهيكل التتظيمي المسئول والإجراءات والعمليات والموارد اللازمة لإدارة

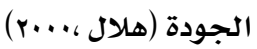

أما إدارة الجودة الشاملة فتعتبرا لأداة الرئيسية التي تؤدي إلى إستراتيجية تطوير العمل

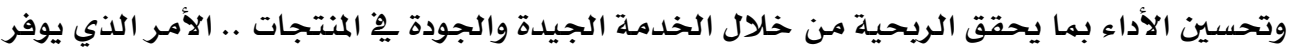

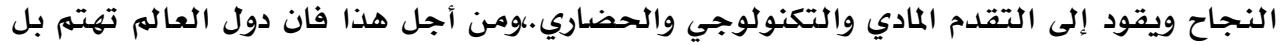

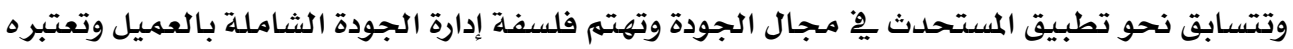

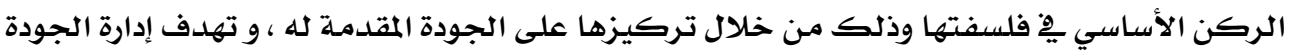

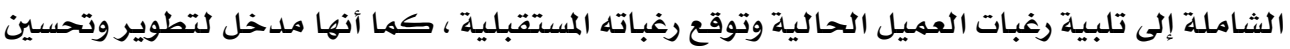

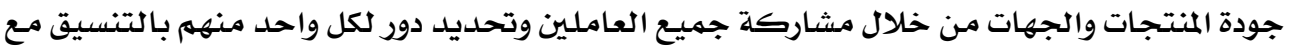

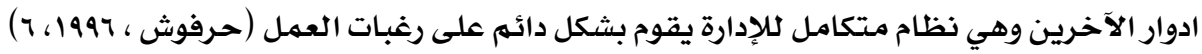

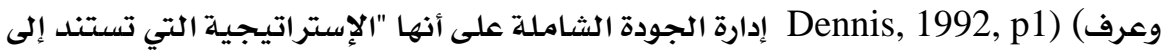

تضافر جهود جميع ويرى (Roger,1992,p12) إن إدارة الجودة الشاملة هي "مجموعة الأعمال على الهال

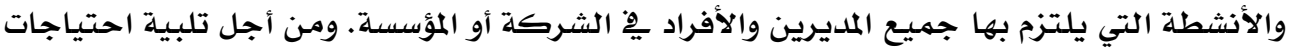

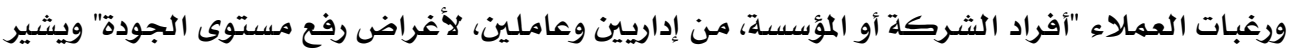

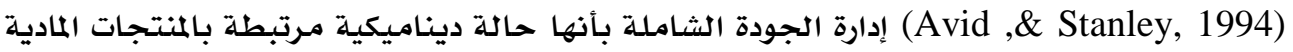

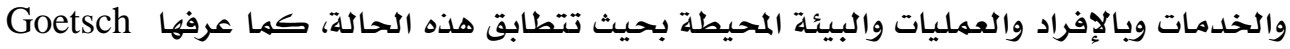

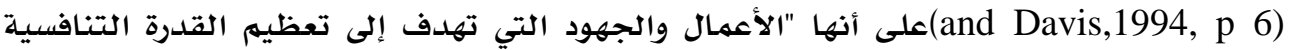

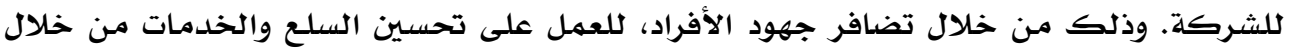

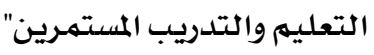

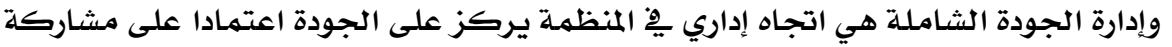

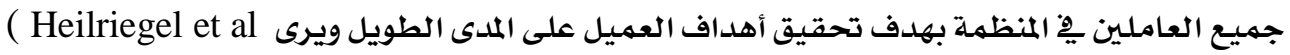

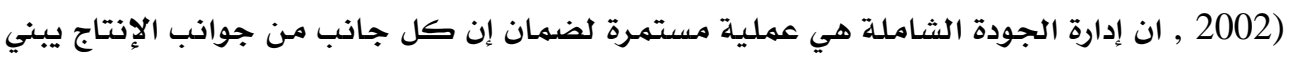

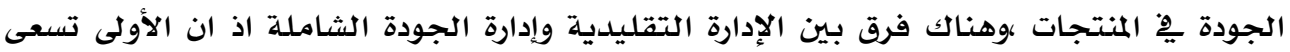

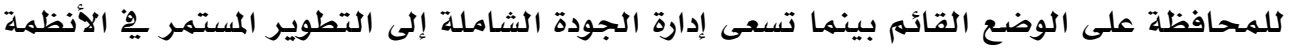

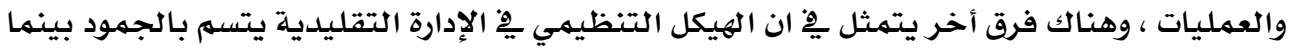

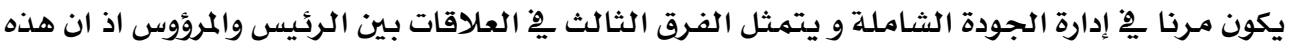

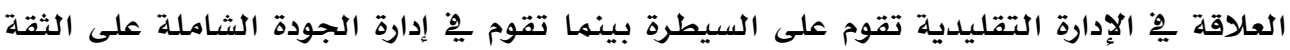

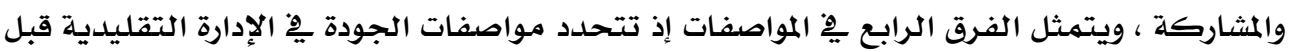


معرفة رغبات المستفيدين بينما تحدد ِِِ إدارة الجودة الشاملة من خلال مساهمة العملاء وأخيرا فان

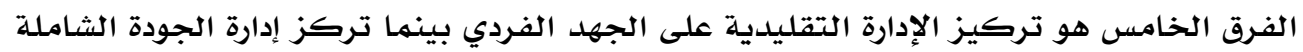

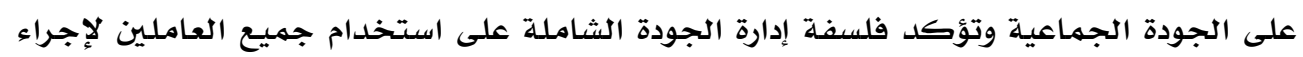

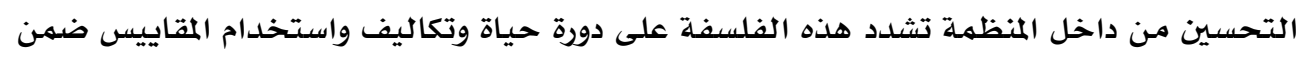

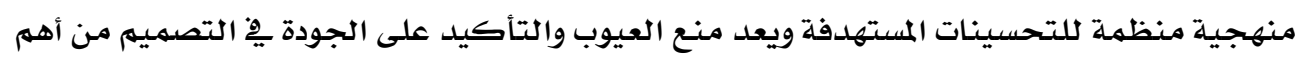

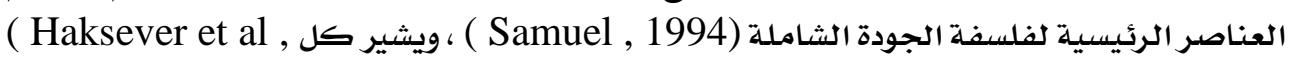

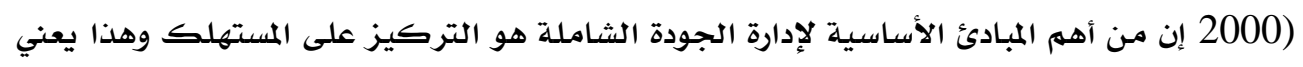

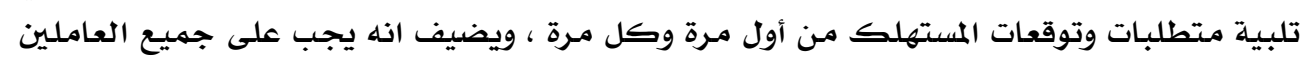

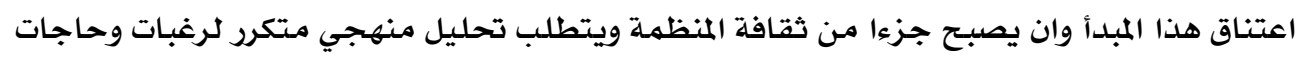

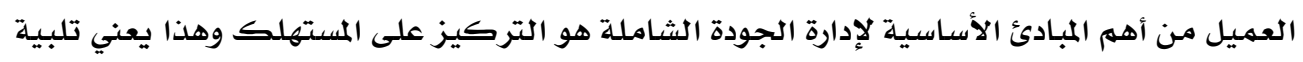

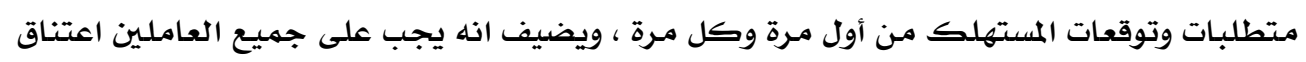

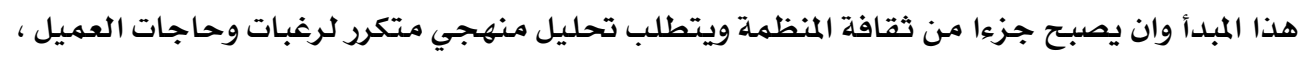

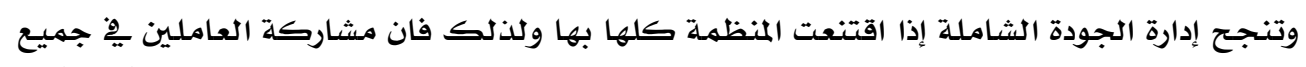

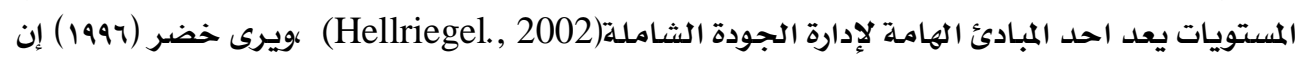

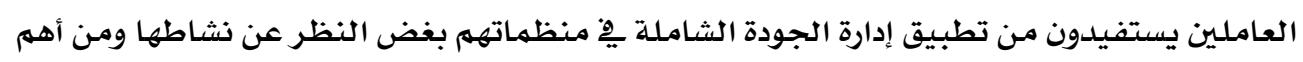

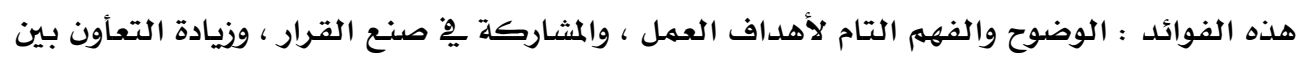

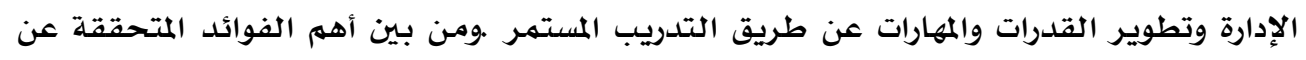

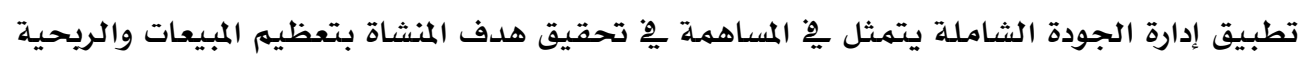

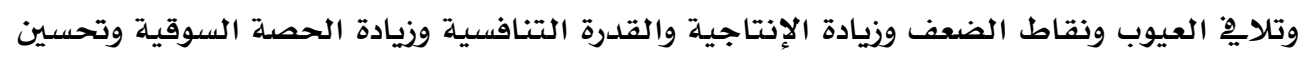

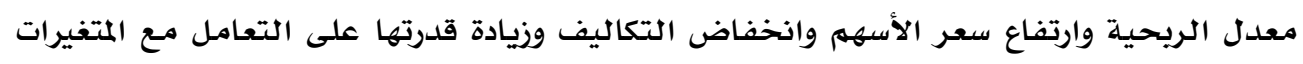

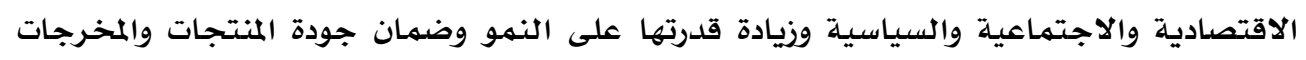

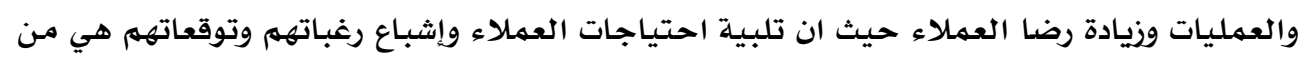

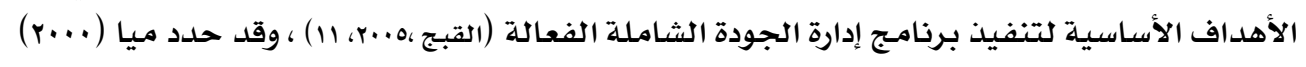

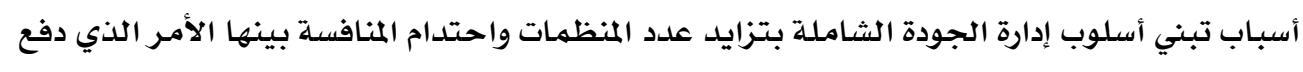

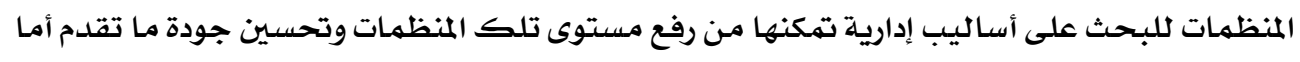

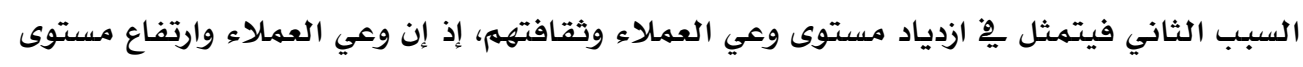

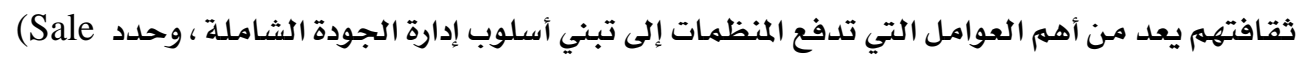

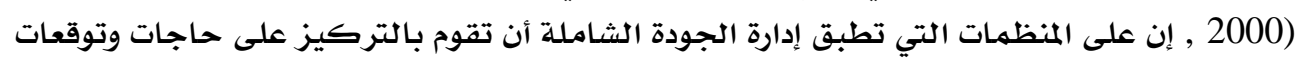

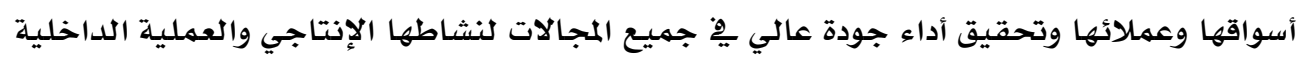

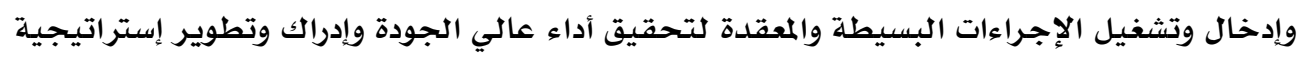

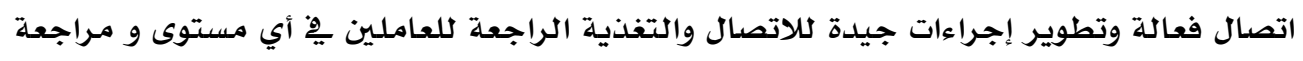

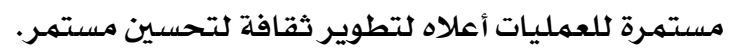


الجودة الشاملة في الخدمات الصحية

يعود تاريخ الاهتمام بجودة الرعاية الصحية إلى عام •114 عندما قامت فلورانس نايتنجيل

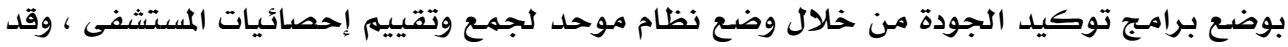

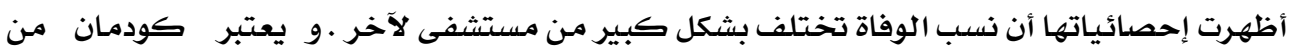

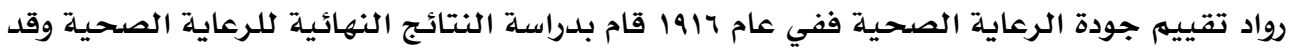

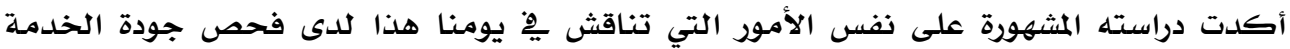
الصحية وتشمل :

• غأهمية ترخيص مقدمي الخدمـة.

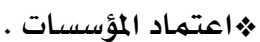

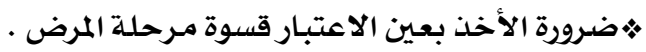

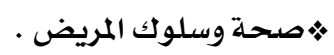

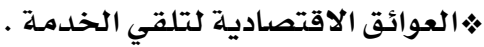

وٌِِ عام 1900 أخذت الهيئة المشتركة يِّ الولايات المتحدة بالضغط على مفهوم التدقيق

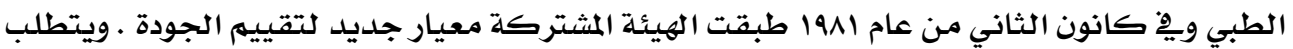

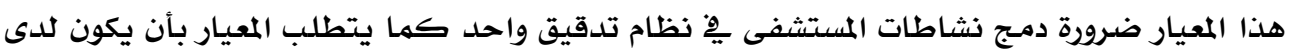

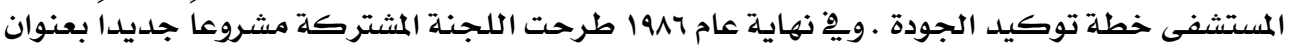

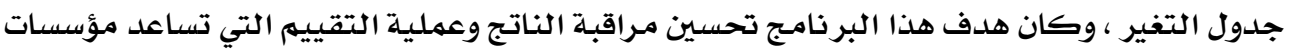

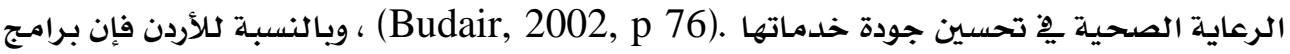

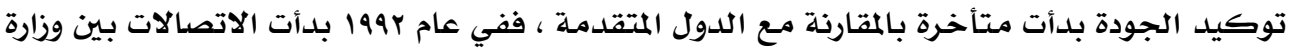

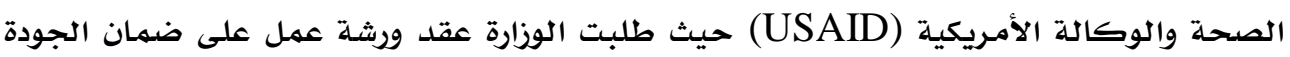

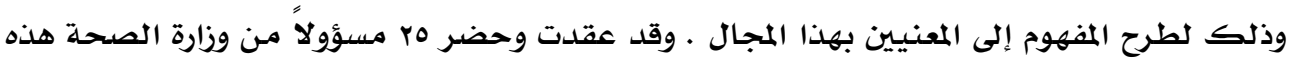

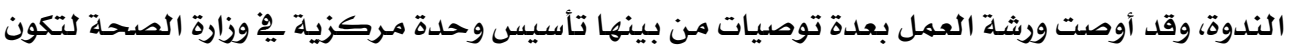

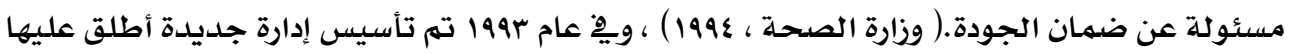

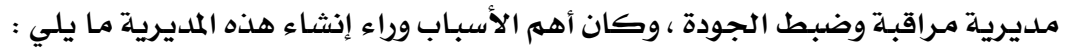

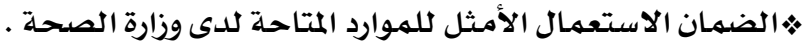

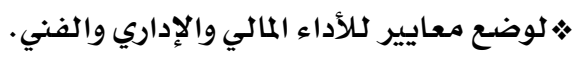

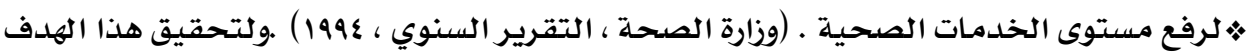

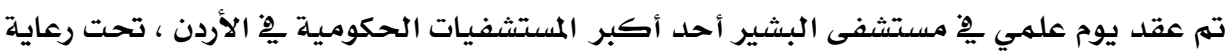

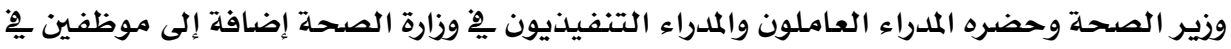

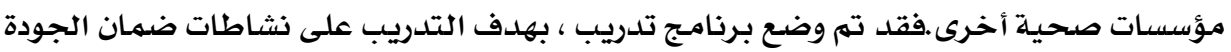

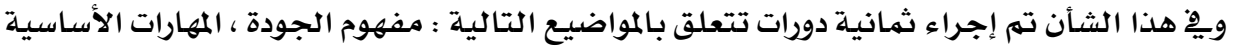

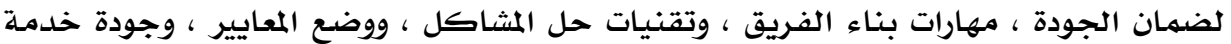


العميل ، والمهارات الأخرى ، وتدريب مدراء الإدارة العليا على ضمان الجودة. لقد أولت وزارة

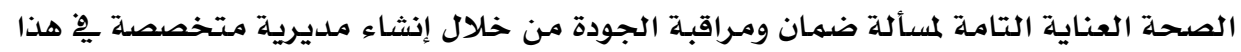

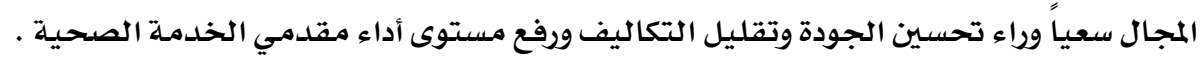
والجودة يِ الخدمات الصحية تشير إلى إيجاد محيط عمل من قبل القادة الصحيين لتعزيز

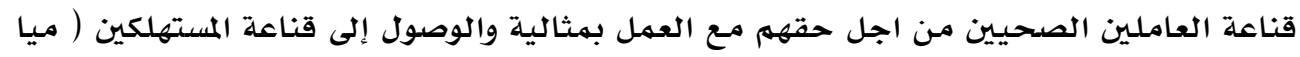

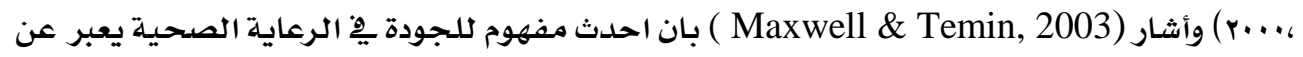

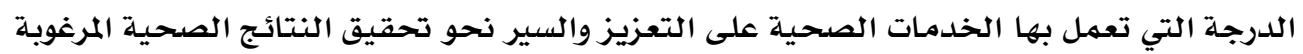

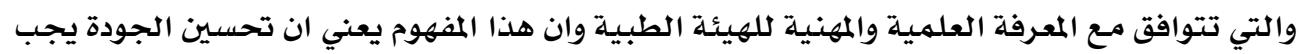

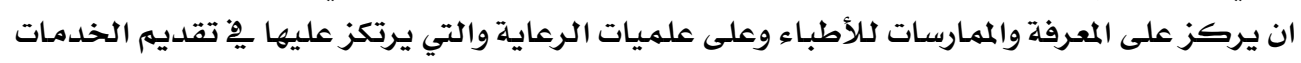

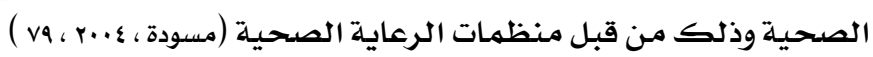

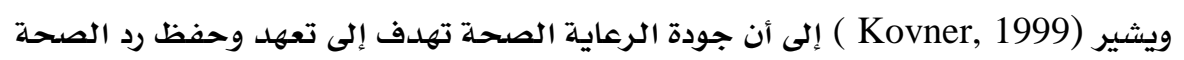

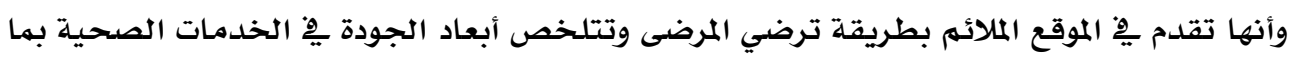

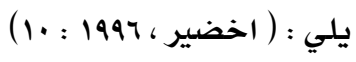

\section{1- الكفاءة الفنية}

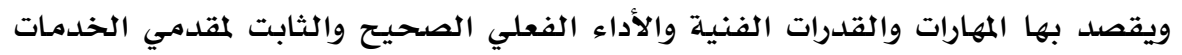

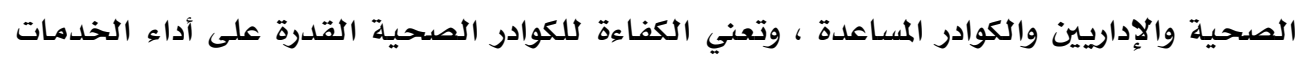

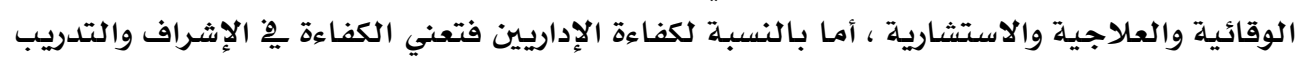

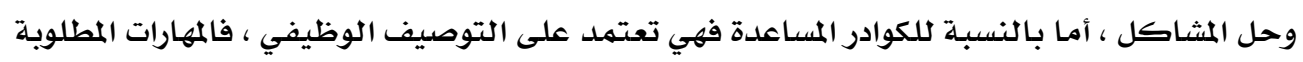

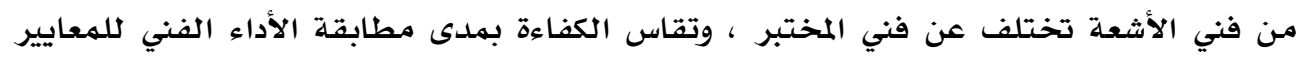

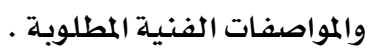

\section{r - ب - بهولة الوصول للخدمات}

يعتبر هذا البعد من أهم الأبعاد ذلك لان صعوبة الوصول إلى المستشفى تؤدي إلى زيادة

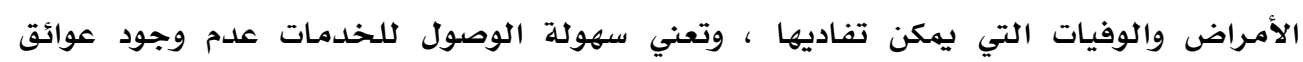

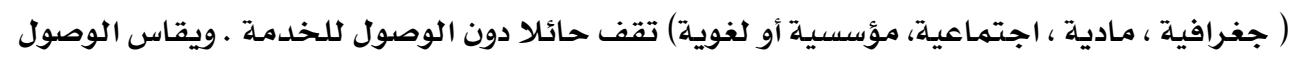

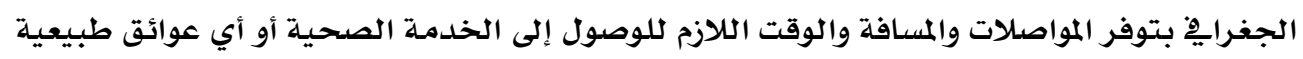

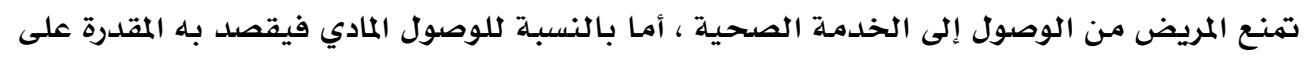

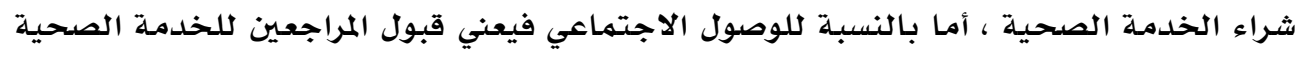

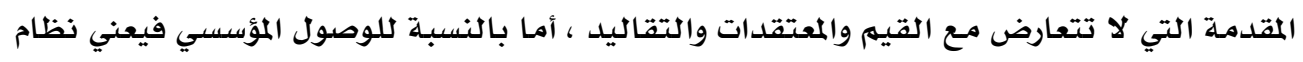

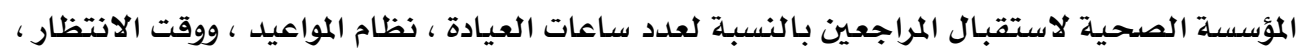

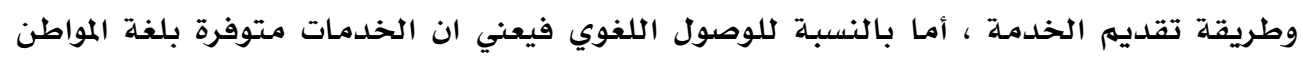

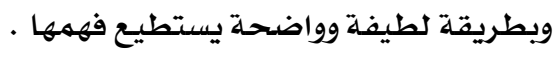




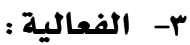

ويقصد بها مدى الحصول على النتائج المرجوة من الإجراء المطبق ، ويقاس من خـلال قسمـة

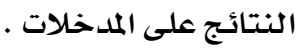

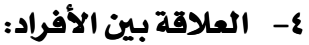

ويقصد به التفاعل بين المراجعين والفريق الصحي وكذلك بين الإداريين والفريق الصحي

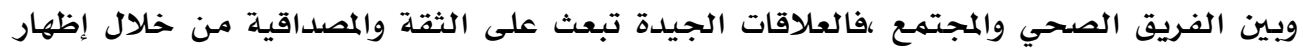

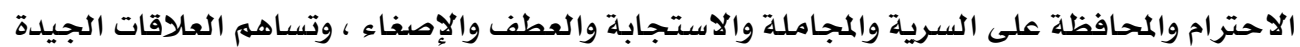

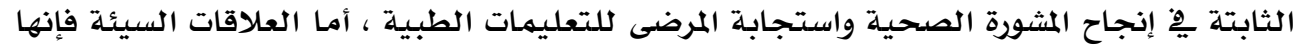

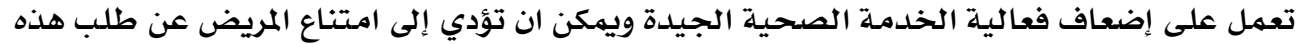

\section{0- الكفاءة باستخدام الموارد :}

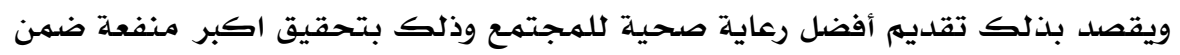

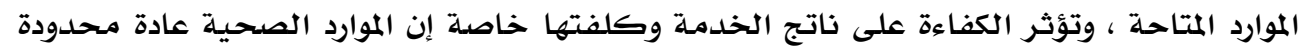

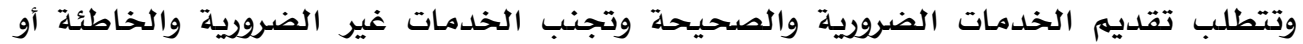

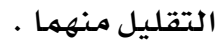

\section{ד- الاستمرارية :}

ويقصد بها تقديم مختلف الخدمات الصحية الضرورية دون تقطع أو توقف ، ويمكن ان

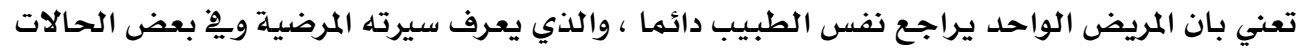
تعني الاستمرارية الاحتفاظ بملفات طبية صحيحة تمكن الطبيب الجديد لواحيد من معرفة السيرة المرضية

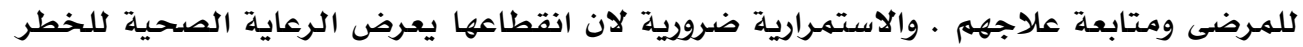

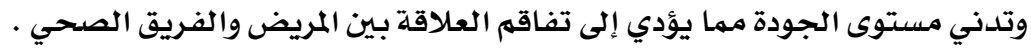

\section{V- السلامة الصحية}

ويقصد بها تقليل خطر التعرض للإصابات والالتهابات وكذلك الأعراض الجانبية أو أي الجاي

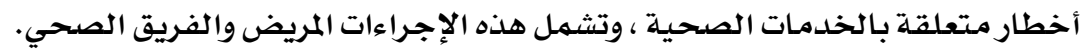
- 1

ويقصد بها مقومات الخدمات التي ليس لها علاقة بالإجراءات الطبية ولكنها تزيد من إقبال

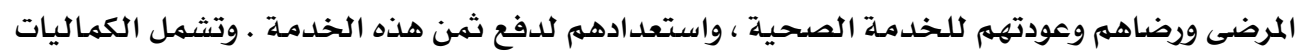

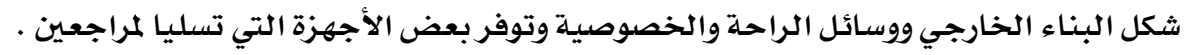
أما مفهوم إدارة الجودة الشاملة يِّ الخدمات الصحية فيشير إلى ثلاث وجهات نظر مكملة

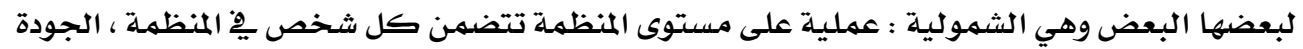

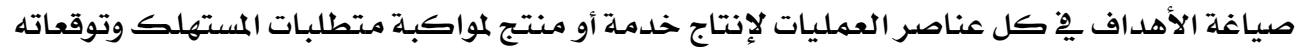


منذ الوهلة الأولى والإدارة لا تعني فقط التزام وتعهد الإدارة العليا بأهداف الجودة فقط بل العمل

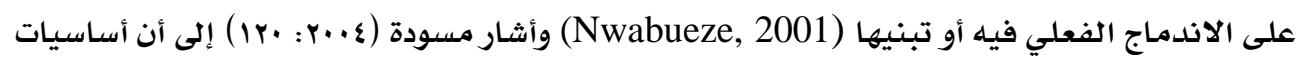

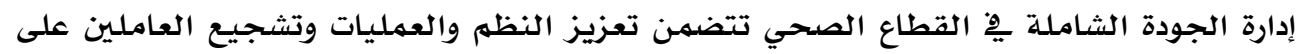

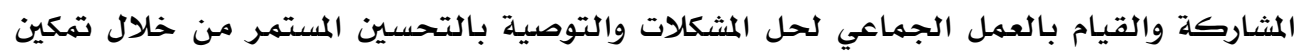

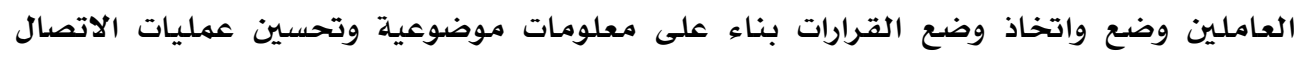

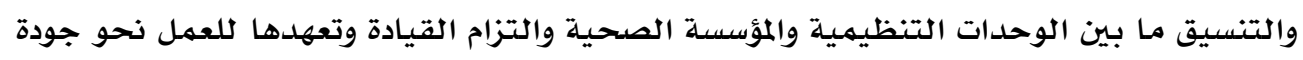

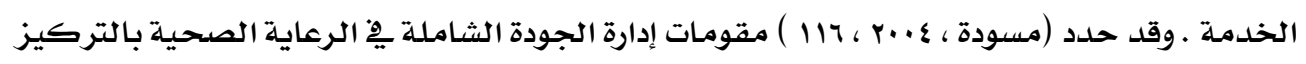

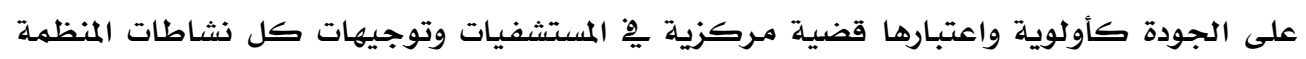

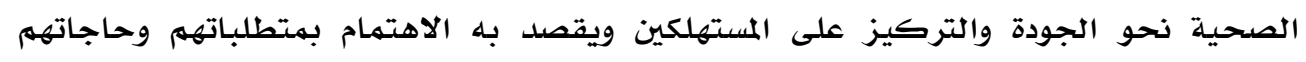

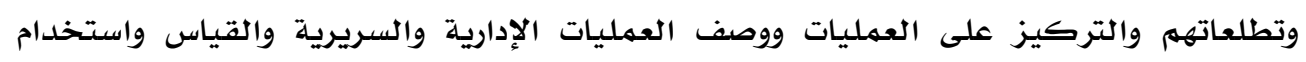

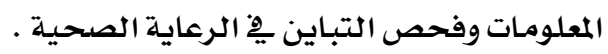

وقد وضع بيرويك عشرة دروس أساسية استوحاها من نظريات الرواد ِِّ الجودة لتطبيقها ِِيْ

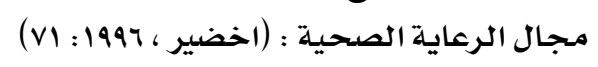

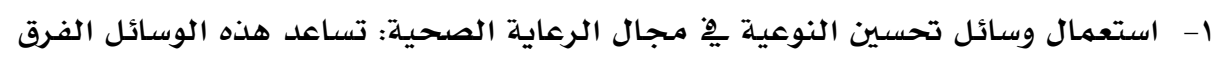

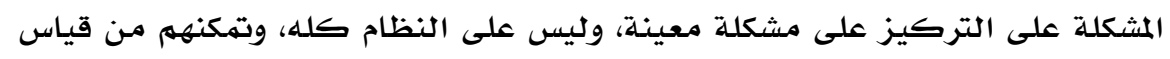

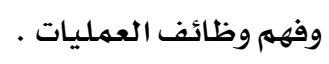

r- أهمية تشكيل الفرق المثتركة من جميع مستويات الوظائف الصحية:لتحسين نوعية

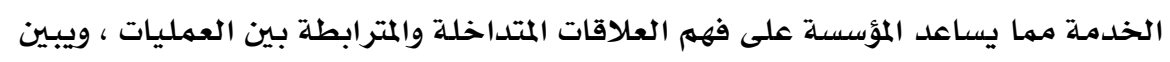

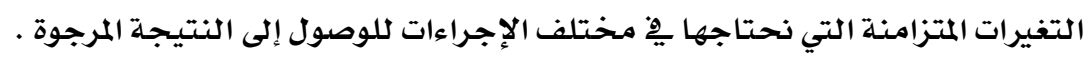

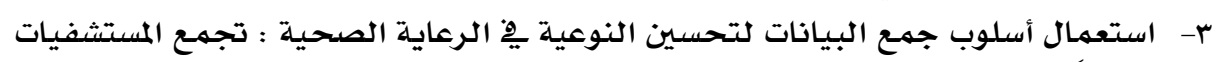

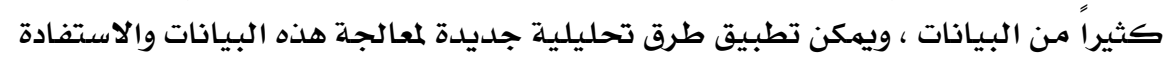

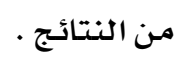

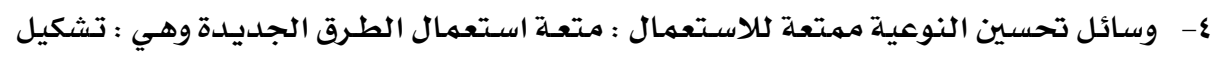

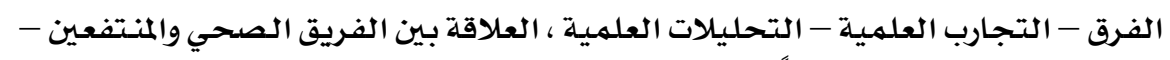

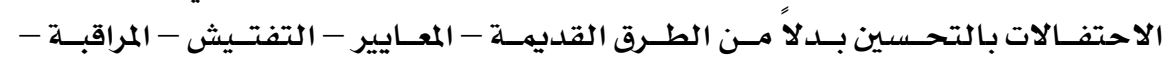

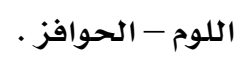

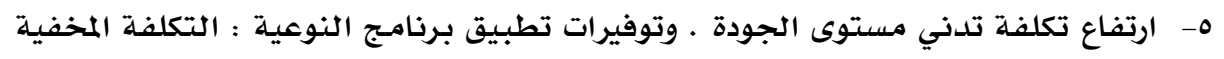

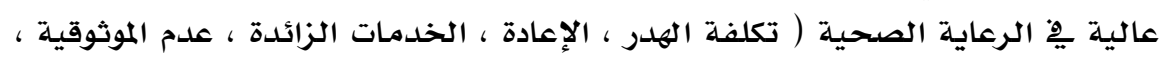

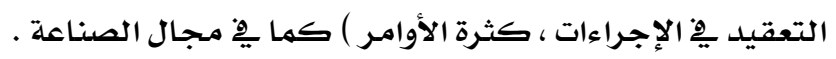

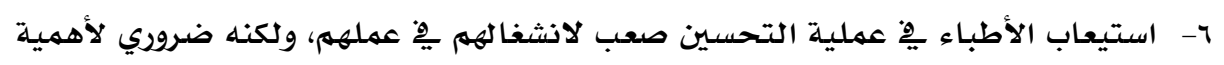

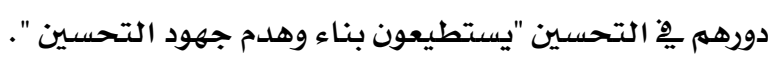

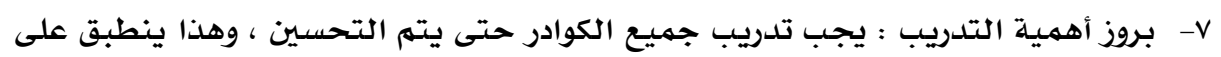

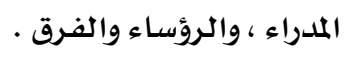


^- الاهتهمام المبكر بتحسين الإجراءات الإدارية والخدمات المساعدة التي تدعم الخدمات

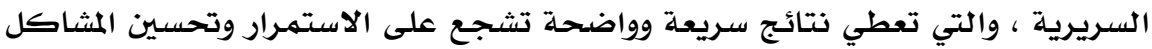

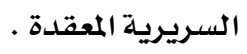

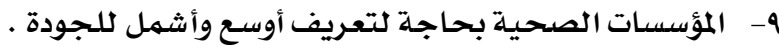

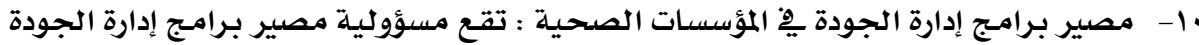

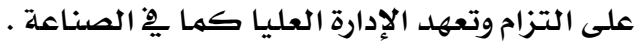

ويرى (Kline, 1992) أن تطبيق إدارة الجودة الشاملة ِِّ المستشفيات الحكومية تتطلب

إجراء بعض التغييرات كالتركيز على تحسين العمليات والاهتمام الزائد بالإنتاجية وتقليل تكلفة

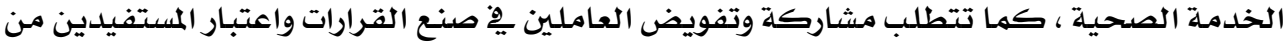

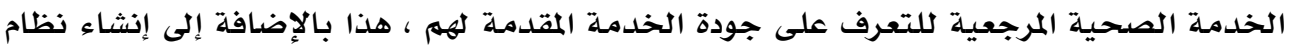

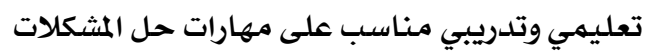

\section{ب ب اللدراسات السابقة}

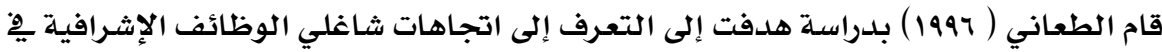

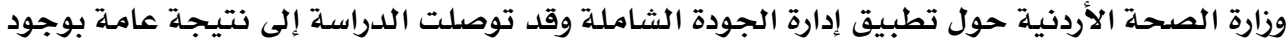

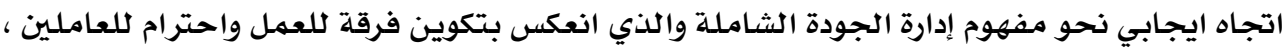

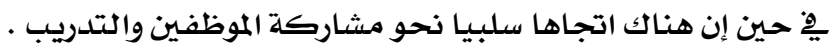
أما دراسـة منصور(199v) فقد هدفت إلى مقارنة تطبيق إدارة الجودة الشاملة بين مستشفيات

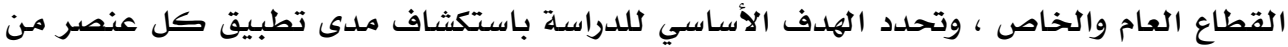

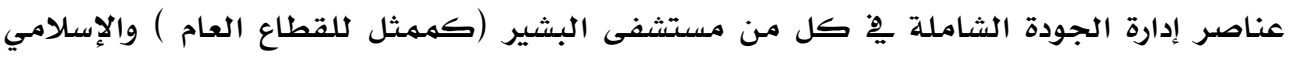

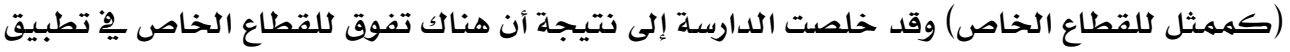

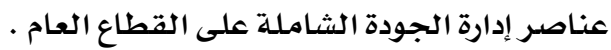
وقام سلامـة (1999) بدراسـة توصلت إلى وجود فروق ذات دلالة إحصائية بين توقعات العاملين

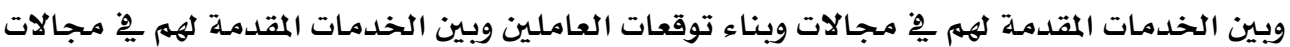

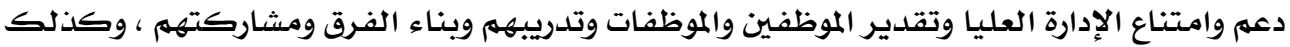

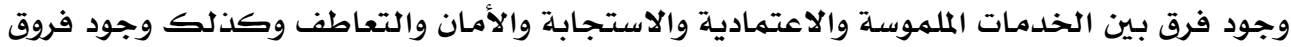

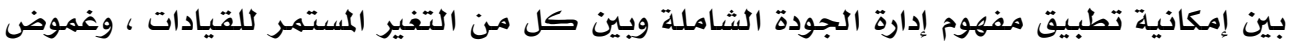

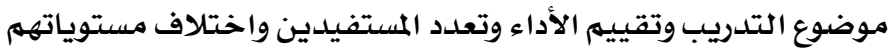

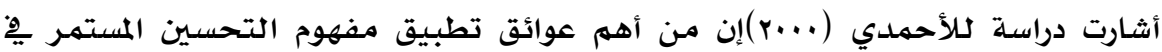

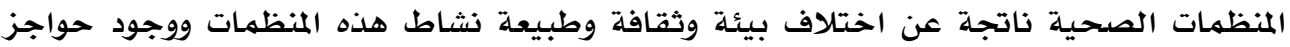

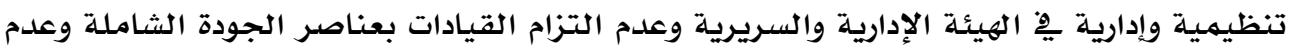

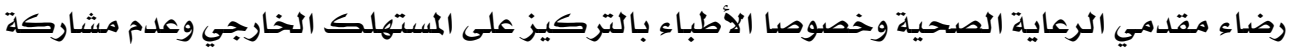


الأطباء ِِّ جهود التحسين المستمر ونقص ِِّ التدريب على مبادئ الجودة وحصرها ِِِ الجوانب

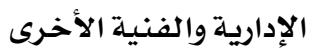

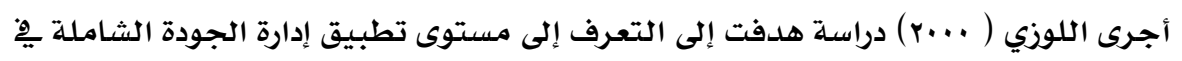

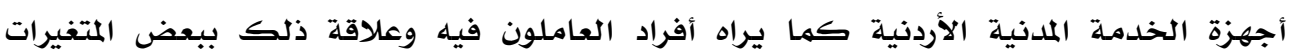

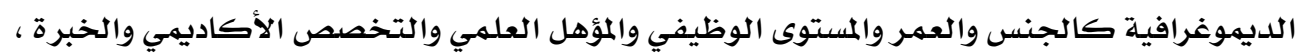

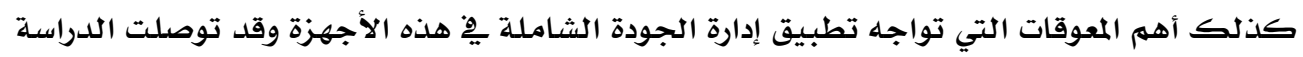

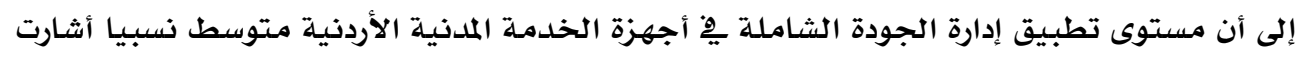

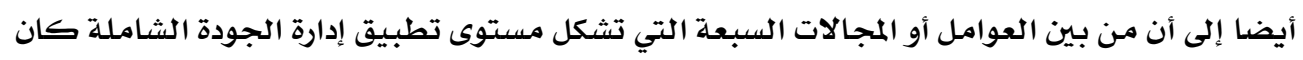

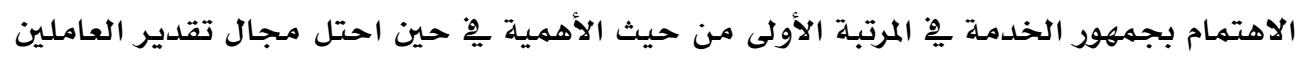

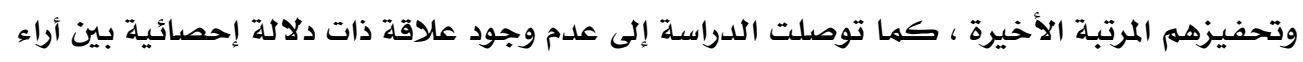

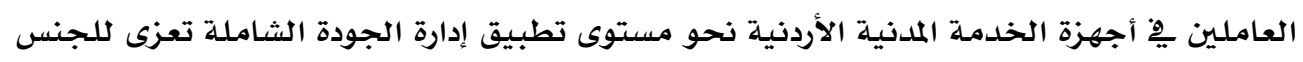

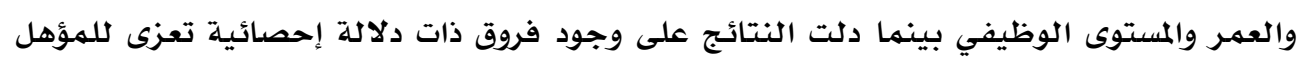

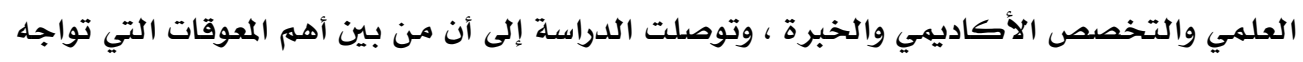

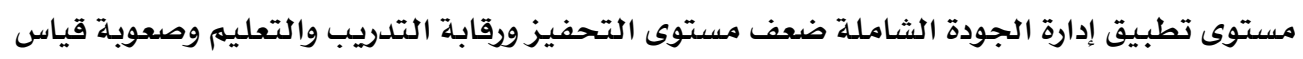

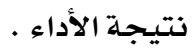

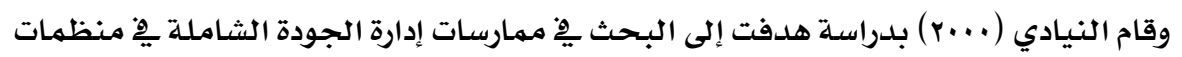

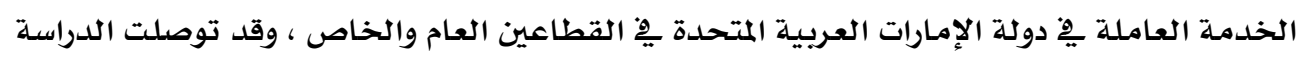

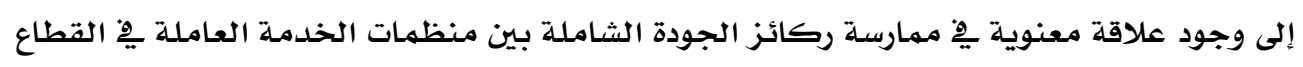

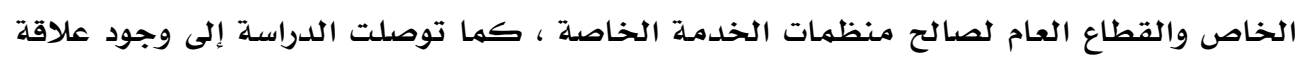

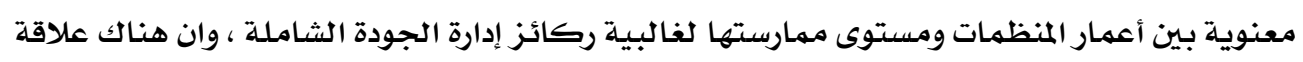

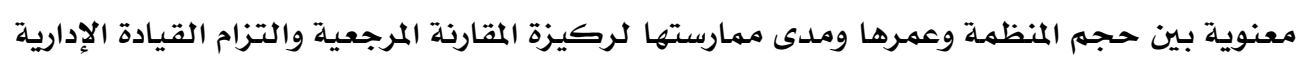

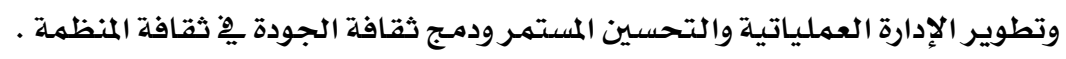

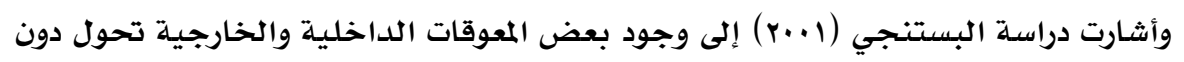

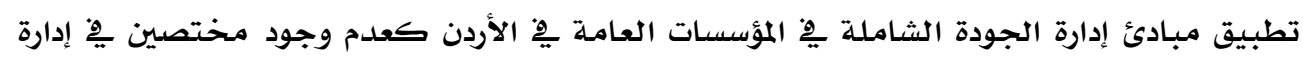

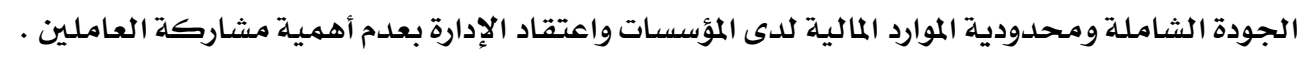

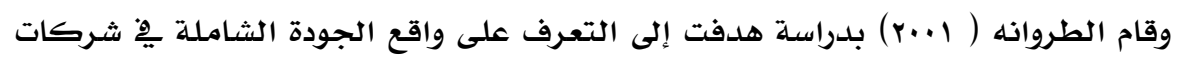

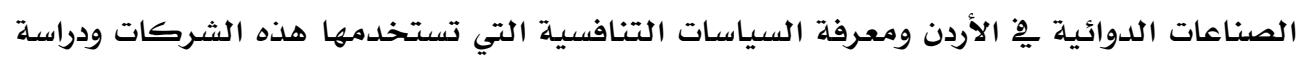

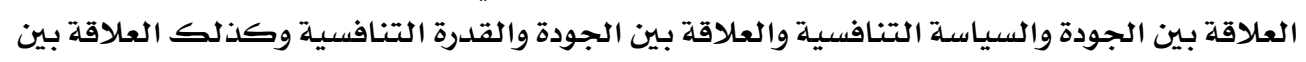

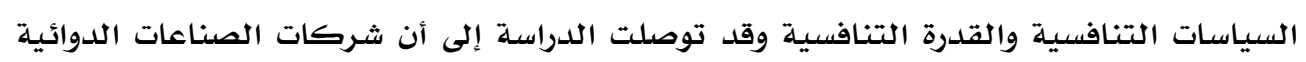

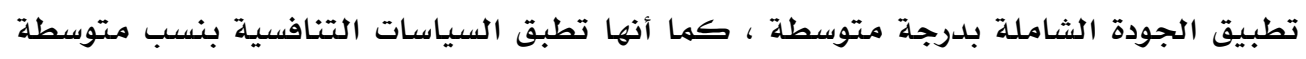

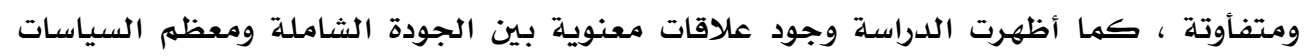




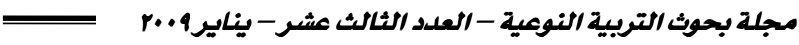

التنافسية لعكس تلك الموجودة بين الجودة الشاملة والقدرة التنافسية وكذلك بين السياسات

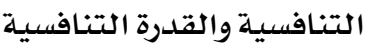

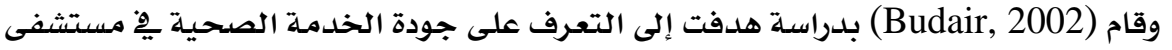

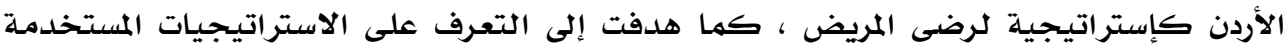

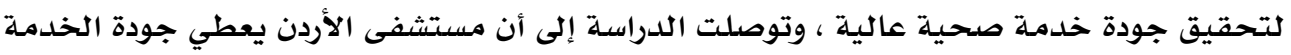

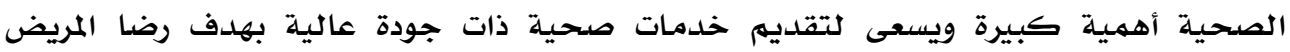
والاحتفاظ به .

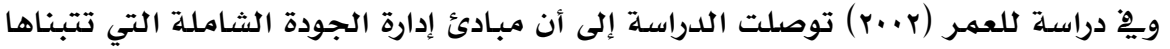

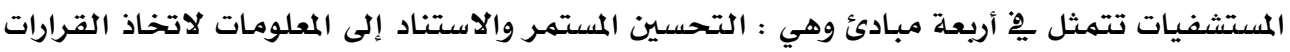

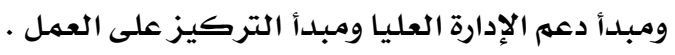

كما قام (Ahmet, 2005) دراسة هدفت إلى البحث ِِّ علاقة الجوانب الملموسة وغير

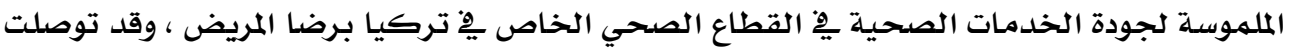

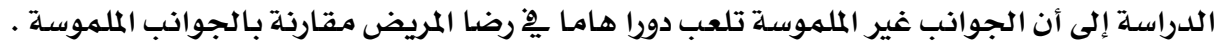

\section{فرضيات اللدراسة :}

بناء على مشكلة الدراسة وأهدافها فقد تمت صياغة الفرضيات التالية:

ا- المستشفيات الخاصة الأردنية لا تطبق إدارة الجودة الشاملة

r- المستشفيات الخاصة الأردنية لا تواجه صعوبات ومعوقات يِّ تطبيق إدارة الجودة الشاملة

\section{مجتمع وعينة اللدراسة :}

تألف مجتمع الدراسلة من جميع المديرين ومساعديهم مِّ المستشفيات الخاصلة وقد تم

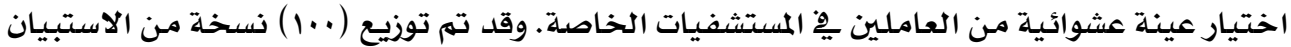

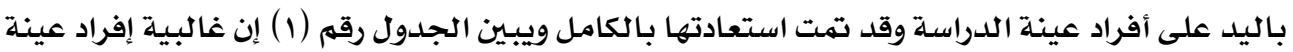

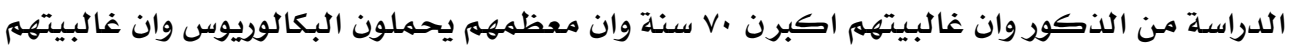

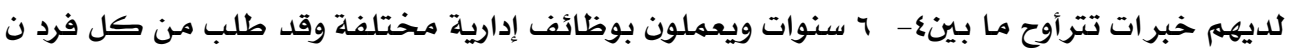

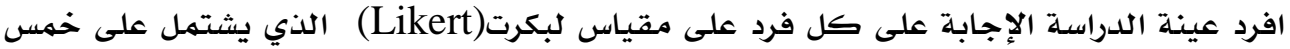

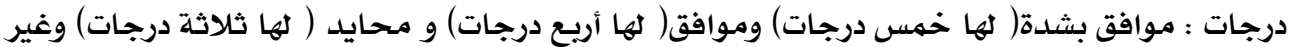
موافق( لها درجتان ) وغير موافق (درجة واحدة لهات مورة) وموافق 
جدول رقم (1)

\begin{tabular}{|c|c|c|c|}
\hline النسبـة & التتكرار & الخيارات & \\
\hline$\% \times 1$ & vi & ذكر & \multirow[t]{3}{*}{ الجنس } \\
\hline$\%$ rq & rq & أنثى & \\
\hline$\% 1 \ldots$ & $1 \ldots$ & المجهوع & \\
\hline$\%$ & 7 & أقل مـن هץ سـنـة & \multirow[t]{3}{*}{ العمر } \\
\hline$\% v$. & v. & דr- هץ سنـة & \\
\hline$\%$ \% & $r \varepsilon$ & צب- 0 0ـ سنة & \\
\hline$\% 1 \ldots$ & $1 \cdots$ & المجمهوع & \multirow[t]{5}{*}{ المؤهل العلهي } \\
\hline$\% \wedge 0$ & ^૦ & بكالوريوس & \\
\hline \% & r & ماجستير & \\
\hline$\%$ & r & دكتوراه & \\
\hline$\% 1 \ldots$ & $1 \ldots$ & المجموع & \\
\hline$\% 9$ & 9 & 1- بنـة & \multirow[t]{4}{*}{ سنوات الخبرة } \\
\hline$\%$ \% & $7 V$ & ع- سنوات & \\
\hline$\%$ Y $\varepsilon$ & $r \varepsilon$ & $9-V$ & \\
\hline$\% 1 \ldots$ & $1 \cdots$ & المجموع & \\
\hline$\%$ & I & مسـاعد مدير & \multirow[t]{5}{*}{ المركز الوظيفي } \\
\hline$\%$ rr & rr & مدير إداري & \\
\hline$\% 19$ & 19 & مدير فني & \\
\hline$\%$ Ү & YA & طبيب & \\
\hline$\% 1 \ldots$ & $1 \ldots$ & المحموع & \\
\hline
\end{tabular}

\section{أسلوب جمع البيانات :}

أ- البيانات الثانوية : اعتمد الباحثان يِّ الحصول على هذه البيانات على الأسلوب المكتبي لبناء

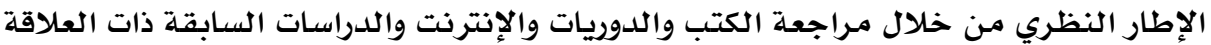

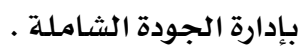

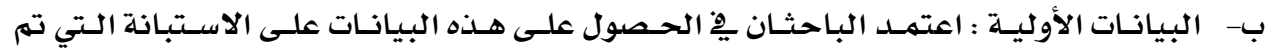

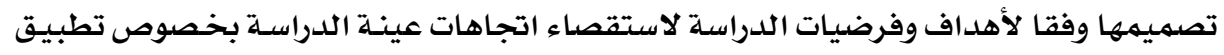

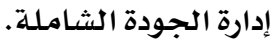




\section{معالجة وتخليل البيانات : - م البيات}

لتحقيق أهداف هذه الدراسـة والتعرف على مـدى تطبيق المستشفيات الخاصـة لإدارة الجـودة

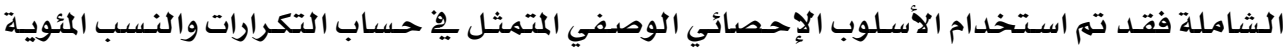

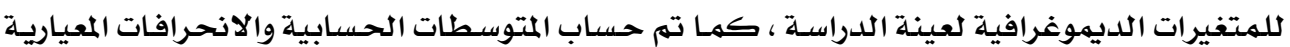

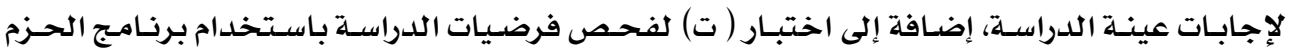
الإحصائية للعلوم الاجتماعية المعروف بـ (SPSS)

\section{التحليل الإحصائي لبيانات الدراسة :}

يظهر الجدول رقم (ץ )المتوسط الحسابي والانحراف المعياري لكل عبارة من العبارات التي

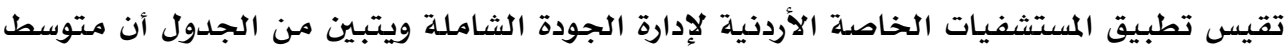

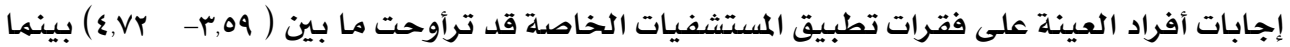

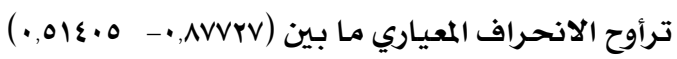

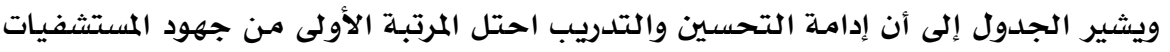

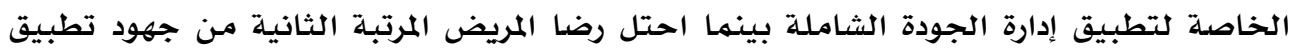

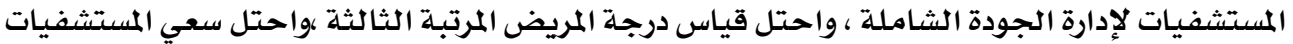

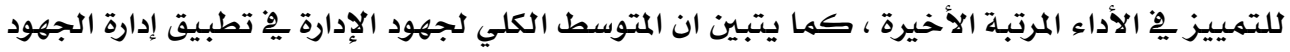

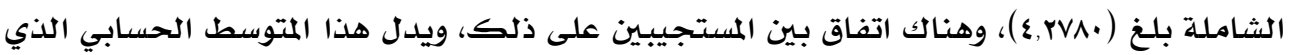

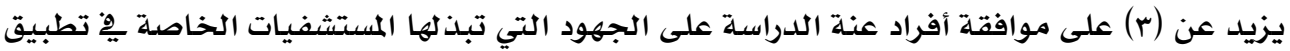

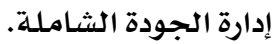


جدول (r) المتوسطات الحسابية والانحرافات المعيارية لإجابة عينة الدراسة

حول تطبيق المستشفيات الخاصة لإدارة الجودة الشاملة

\begin{tabular}{|c|c|c|c|}
\hline الانحراف & المتوسط & 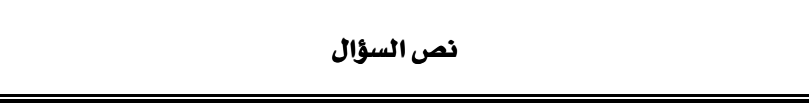 & 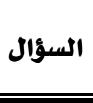 \\
\hline - oquar & $\varepsilon, \varepsilon \vee \cdots$ & يتوافر لدى المستشفى خطة لتحسين مستوى أداء الخدمة الصحية المقدمة & 1 \\
\hline$\cdot$, TVRIr & $\varepsilon, r_{1} \ldots$ & تشكل جودة الخدمة الصحية إستراتيجية بالنسبة للشركة & r \\
\hline$\cdot, 01 \varepsilon \cdot 0$ & \&,VY.. & تعمل إدارة المستشفى على إدامة التحسين والتدريب & $r$ \\
\hline •,vı৭^r & \&,rY.. & تدرب إدارة المستشفى العاملين على تقديم خدمة صحية متميزة & $\varepsilon$ \\
\hline$\cdot, 9 \cdot 1 v 9$ & $\varepsilon, \cdot v \cdot \cdot$ & تحرص إدارة المستشفى على إرضاء العاملين & $\bullet$ \\
\hline$\cdot, V \varepsilon V \varepsilon 0$ & $\varepsilon, 1 r .$. & تقوم إدارة المستثفى بتأكيد الجودة للخدمة الطبية المقدمة & 7 \\
\hline$\cdot, \mathrm{V0} 0.79$ & r,^९.. & توفر إدارة المستشفى نظام معلومات حديث & $\checkmark$ \\
\hline דשrדוד, & $\varepsilon, \bullet \varepsilon \ldots$ & تشجع إدارة المستشفى العمل بروج الفرق الواحد & $\Lambda$ \\
\hline$\cdot, \mathrm{V} \cdot \mathrm{IVR}$ & $\varepsilon, 00 \ldots$ & تهدف إدارة المستشفى إلى ضمان مستوى عالي من الجودة & 9 \\
\hline$\cdot, v \varepsilon r \cdot r$ & $\varepsilon, \varepsilon$ «.. & يوجد لدى المستشفى مجلس يهتم بشؤون جودة الخدمات الصحية & 1. \\
\hline •,ARVYY & r.०१... & تسعى إدارة المستشفي إلى التميز دائما ِِ تقديم الخدمات الطبية & 11 \\
\hline$\cdot, \mathrm{V} \varepsilon 79 \wedge$ & $\varepsilon$, Y... & تركز إدارة المستشفى اهتمامها على المريض & ir \\
\hline$\cdot .0910 \mathrm{Y}$ & $\varepsilon, 07 \ldots$ & تقوم إدارة المستشفى بالتركيز على قياس درجة رضا المريض بشكل دوري & ir \\
\hline$\cdot$, TrV7o & $\varepsilon, r \ldots$ & تعمل إدارة المستشفى على تحديد ومعالجة شكأوي المرضى & $1 \varepsilon$ \\
\hline$\cdot$,TMArT & $\varepsilon, \cdot r .$. & تقوم إدارة المستشفى بالتأكيد على تقديم خدمات تتوافق مـع توقعات المدير & 10 \\
\hline$\cdot$ •, Tוra. & $\varepsilon, \pi+$. & يشكل رضا المريض أولوية خاصة للمستشفى & 17 \\
\hline •,ravar & \&,YVA. & المتوسط الكلي & \\
\hline
\end{tabular}

ويظهر الجدول رقم (r )المتوسط الحسابي والانحراف المعياري لكل عبارة من العبارات التي

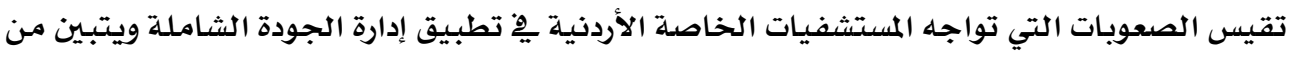

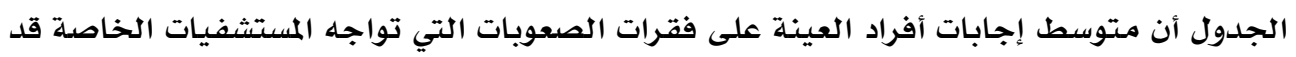

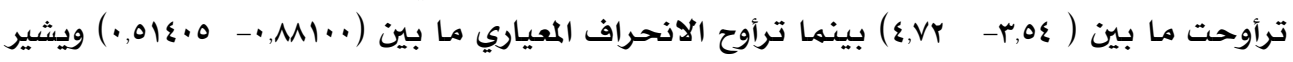

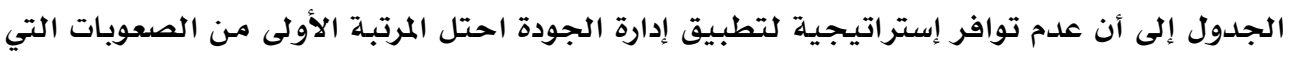

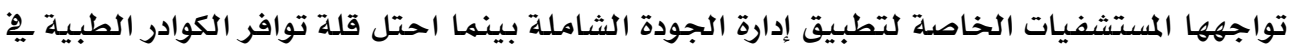

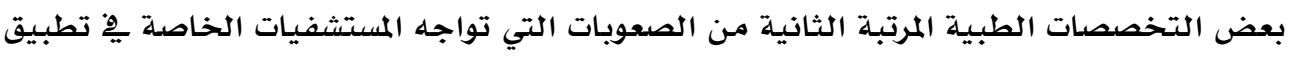

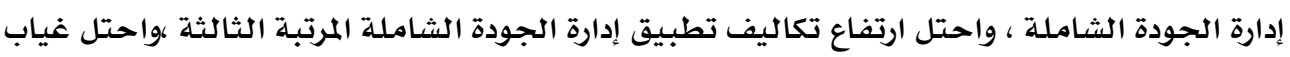

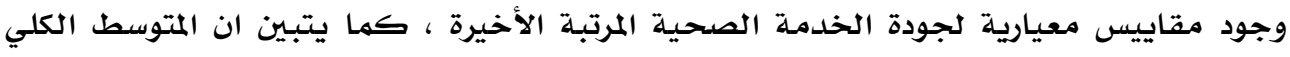

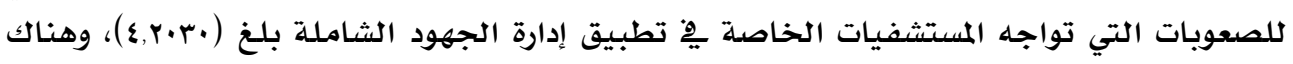


اتفاق بين المستجيبين على ذلك، ويدل هذا المتوسط الحسابي الذي يزيد عن (r) على موافقة أفراد

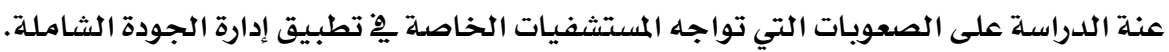
جدول (r) المتوسطات الحسابية والانحرافات المعيارية لإجابة عينة الدراسة حول الصعوبات التي تواجهها المستشفيات الخاصة يو تطبيق إدارة الجودة الشاملة

\begin{tabular}{|c|c|c|c|}
\hline الانحراف & المتوسط & 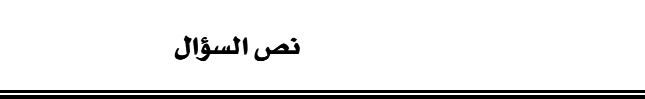 & 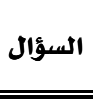 \\
\hline$\cdot, 01 \varepsilon \cdot 0$ & $\varepsilon, \vee r \ldots$ & عدم توافر إستراتيجية معينة لتطبيق إدارة الجودة & iv \\
\hline •,Aiviv & r.91... & قلة الخبرات ِِ المستشفى القادرة على تطبيق إدارة الجودة & M \\
\hline •,W7IT & $\varepsilon, \cdot 7 \ldots$ & نقص الموارد المالية المخصصة لتطبيق إدارة الجودة الشاملة & 19 \\
\hline$\cdot$, VOAVY & $\varepsilon, \cdot 1 \ldots$ & غياب التخطيط السنوي لتحديد احتياجات المستشفى & $r \cdot$ \\
\hline$\cdot, 7117 \mathrm{~V}$ & $\varepsilon, 7 \varepsilon \ldots$ & قلة الكوادر المؤهلة يِ بعض المجالات الطبية & rI \\
\hline$\cdot, \Lambda \cdot \wedge \mathrm{V} r$ & $\varepsilon, 10 \ldots$ & نقص الكوادر ِِ المجالات الطبية المساندة & rY \\
\hline$\cdot, M 1 \cdot$. & r,o\&.. & غياب وجود مقاييس معيارية لجودة الخدمة الصحية & rr \\
\hline •,AYIIA & $\varepsilon, 1 \Lambda \ldots$ & قصور برامج التدريب والتحسين المستمر & rq \\
\hline •,AYO.० & $\varepsilon, 19 \ldots$ & ارتفاع تكاليف تطبيق إدارة الجودة الشاملة & ro \\
\hline$\cdot, \bullet \varepsilon q \vee \wedge$ & $\varepsilon, r \cdot r \cdot$ & المتوسط الكلي & \\
\hline
\end{tabular}

اختبار الفرضيات

$$
\text { الفرضية الأولى }
$$

Ho

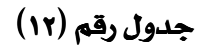

نتائج اختبار الفرضية الأولى

\begin{tabular}{|c|c|c|c|}
\hline نتيـجـة الفرضية العدمية & (ألفا) Sig. & T الجدولية & T المحسوبة T \\
\hline رفض & صفر & $1,9 \wedge \varepsilon Y$ & $M V,|Y|$ \\
\hline
\end{tabular}

تم استخدام اختبار One SampleT-Test وتدل نتائج الاختبار كما يبينها الجدول رقم

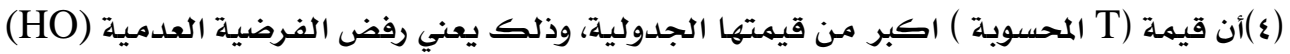

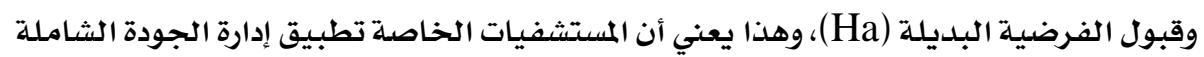
الفرضية الثانية

Ho لأتواجه المستشفيات الخاصة الأردنية صعوبات يِّ تطبيق إدارة الجودة الشاملة 


\section{جدول رقم (0)}

\section{نتائج اختبار الفرضية الثانية}

\begin{tabular}{|c|c|c|c|}
\hline نتيـجة الفرضيـة العدمية & Sig. & T الجدولية T & المحسوبة T \\
\hline رفض & صفر & $1,9 \wedge \varepsilon r$ & $Y \varepsilon, 171$ \\
\hline
\end{tabular}

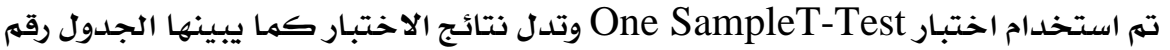

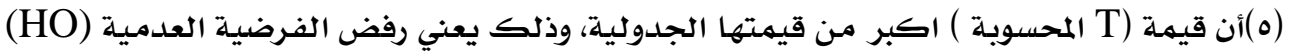

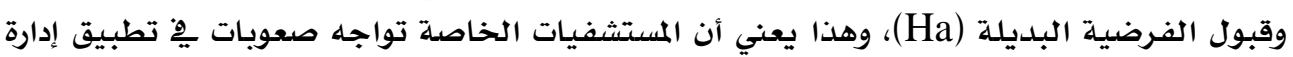
الجودة الشاملة.

\section{تتائج وتوصيات الدراسة}

هدفت هذه الدراسـة إلى التعرف على مدى تطبيق المستشفيات الخاصـة ألأردنية لتطبيق إدارة

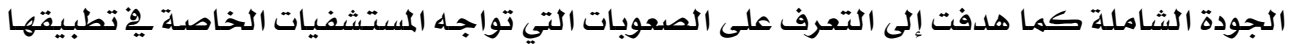

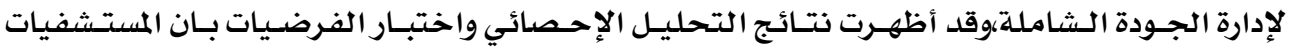

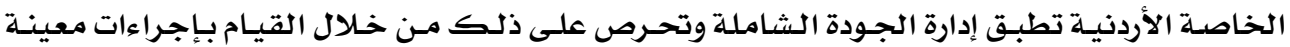

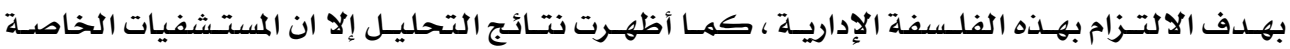

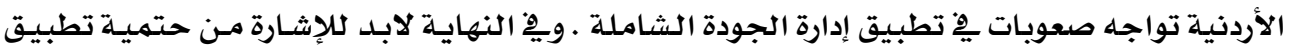

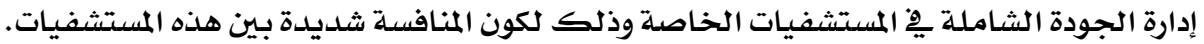

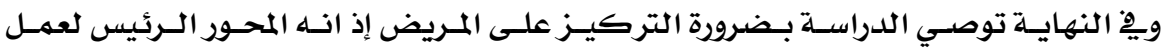

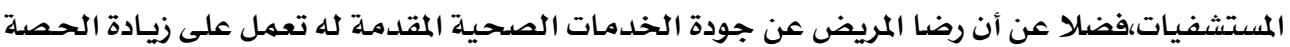

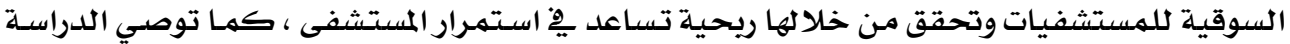

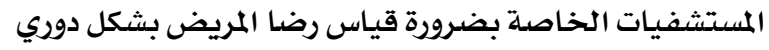

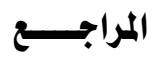

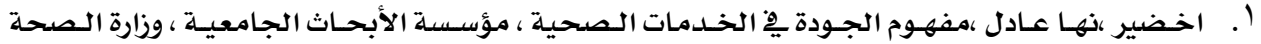
الأردنية ، عمان 1998.

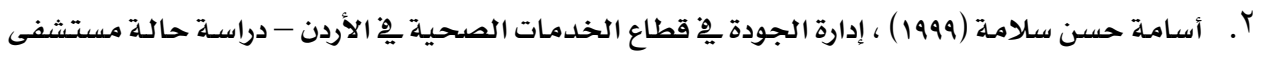
الجامعة الأردنية رسالة ماجستير - جامعة آل البيت

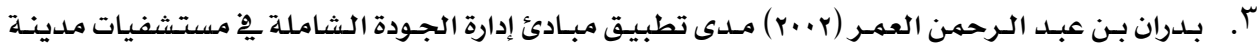

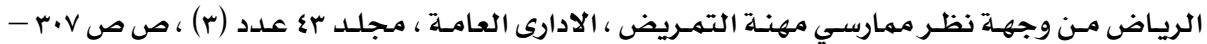

rol

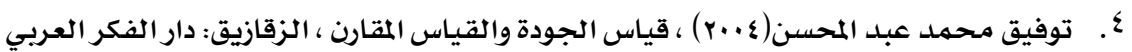




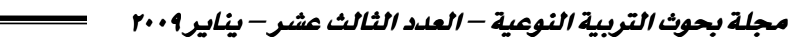

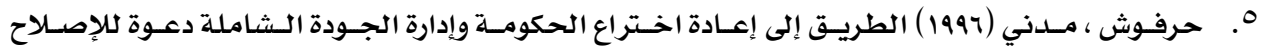

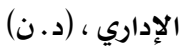

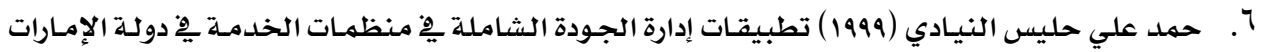

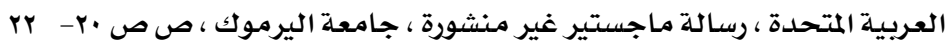

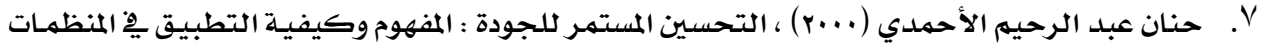

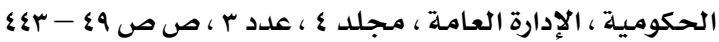

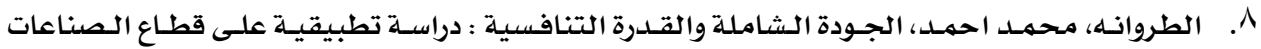

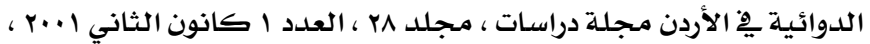

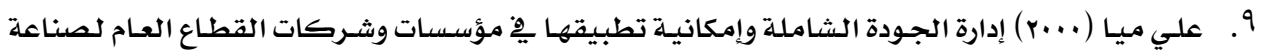

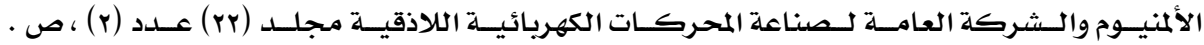
VY • ( . موسى اللوزي ، ( 1999) التطوير التنظيمي ،اتجاهات المديرين نحو تطبيق مبادئ إدارة الجـودة الشاملة

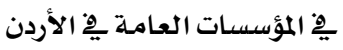

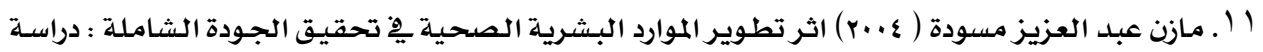

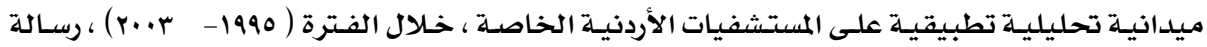
دكتوراه غير منشورة ، جامعة السودان للعلوم والتكنولوجيا ، الخرطوم

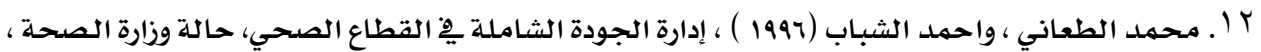

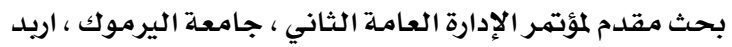

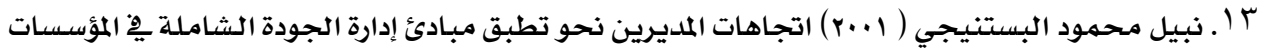

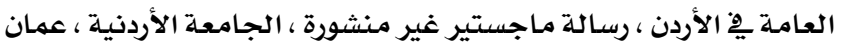

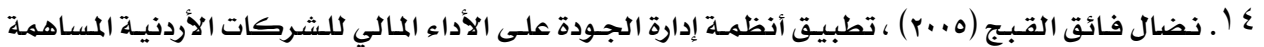

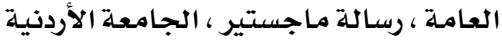

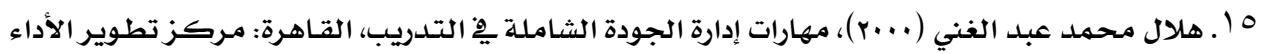
والتنهيـة

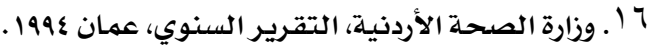

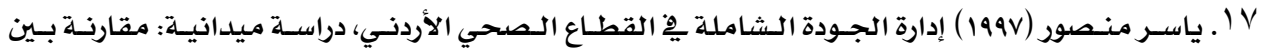
مستشفى البشير والإسلامي رسالة دكتوراه، جامعة بغداد

18. Ahmet Kara, Subhash Lonial , Mehves Tarim ,Selim Zaim ( 2005) Service quality in Turkey, European Business Review Vol. 17 No. 1, 2005 Emerald Group Publishing Limited ,pp. 5-20

19. Ashok, R. ( 1996) , Total quality Management: A cross functional Perspective , John Wiley and Sons

20. Avid, G. and Stanley, D. (1994), Total quality. New York : Macmillan college Publishing 
21. Colin, M. and Stephen. M ( 1994), Total quality Management in the public sector , : an International Perspective , Open University Press ,Philadelphia

22. David, L. Goetsch and Stanley, Davis ( 1994) Introduction to total quality, Singapore : Prentice - Hall International , Inc. p6

23. Dennis C. Kinlow , (1992) Continuous Improvement and

24. Don Hellriegel, Susan E. Jackson, John W. Slocum , JR. ( 2002), Management ,A Competency - Based Approach, South- Western.

25. H., Samuel K.M. ( 1994), The ISO series for Total Quality Management International Journal of quality \& Reliability Management, Vol. 11 No. 9

26. Haksever, C., Render, B, Russell S, Murdick G., (2000) Service Management and Operations, Prentice Hall, New Jersey, 2nd Edition, ISBN 0130813389.

27. James Maxwell \& Peter Temin ( 2003) Corporate Management of quality in Employee Health Plans, HealthCare Management Review, Volume 28, Issue 1, PP28-29.

28. Kovner, A.R. (1999) Health Care Delivery in the United Sates, 6th. Ed. Spring Publishing Company.

29. Nwabueze, U. ( 2001) The Implementation of TQM For NHS Manager, total Quality Management, Vol 12, Issue 5 , pp 657-666

30. Roger Tanks, (1992) Fast Track To quality, New York : McGraw -Hill Inc, P 12

31. Russell, R. S \& Bernard W. Taylor III. (2001). Operation Management: Focusing on Quality and Competitiveness. Prentice Hall. Upper Saddle River, New Jersey

32. Sale, D. N. T. (2000). Quality Assurance: A Pathway to Excellence. First published. Macmillan Press Ltd. London. Printed in Malaysia.

33. Salim Budair, total quality Management in HealthCare, MSC. Thesis , Hudersfield University, 2002.

34. Slack, N. Chambers, S. Johnston, R. (2001) Operations Management. Third Edition. Prentice Hall 